\title{
Nutrient intake and dietary patterns of relevance to dental health of 12-year-old Libyan children
}

\author{
Rasmia Huew ${ }^{1}$, Anne Maguire ${ }^{1}$, Paula Waterhouse ${ }^{1}$ and Paula Moynihan 1,2,3,* \\ ${ }^{1}$ Centre for Oral Health Research, Newcastle University, Newcastle upon Tyne, UK: ${ }^{2}$ Institute for Ageing and \\ Health, School of Dental Sciences, Newcastle University, Framlington Place, Newcastle upon Tyne NE2 4BW, UK: \\ ${ }^{3}$ Human Nutrition Research Centre, Newcastle University, Newcastle upon Tyne, UK
}

Submitted 20 July 2012: Final revision received 28 January 2013: Accepted 30 January 2013: First published online 3 April 2013

\begin{abstract}
Objective: There are few data on the dietary intake of children in Libya, and none on free sugars intake. The present study aimed to report the intake of macronutrients and eating habits of relevance to dental health in a group of Libyan schoolchildren and to investigate any gender differences for these variables.

Design: Dietary information was obtained from a randomly selected sample using an estimated $3 \mathrm{~d}$ food diary. Dietary data were coded using food composition tables and entered into a Microsoft ${ }^{\circledR}$ Access database. Intakes of energy, macronutrients, sugars and the amount of acidic items consumed were determined using purposewritten programs.

Setting: Benghazi, Libya.

Subjects: Schoolchildren aged 12 years.

Results: One hundred and eighty children (ninety-two boys and eighty-eight girls) completed the study. Their mean age was $12 \cdot 3$ (SD 0.29) years. The average daily energy intake was 7.01 ( $\mathrm{sD} 1.54) \mathrm{MJ} / \mathrm{d}$. The percentage contributions to energy intake from protein, fat and carbohydrate were 16\%, 30\% and 54\%, respectively. Total sugars contributed $20 \cdot 4 \%$ of the daily energy intake, and free sugars $12 \cdot 6 \%$. The median daily intake of acidic items was $203 \mathrm{~g} / \mathrm{d}$, and of acidic drinks was $146 \mathrm{~g} / \mathrm{d}$. There were no statistically significant differences in nutrient intakes between genders. Intake of acidic items was higher in girls $(P<0 \cdot 001)$.

Conclusions: The contribution to energy intake from macronutrients was in accordance with global nutrition guidelines. The acidic drinks intake was low compared with other populations, while free sugars intake was above the recommended threshold of $10 \%$ of energy intake.
\end{abstract}

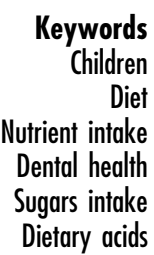

Following the discovery and export of oil in Libya in the 1960s, the national Libyan income has increased. As a result, the whole lifestyle of the nation has changed with many goods and foodstuffs now being imported. Consequently food, culture and customs have changed and have become 'Westernised' in terms of consumption of sweets, acidic sugary drinks and food and confectioneries. All types of sticky, sweet foods and acidic drinks are now commonly available in school canteens. Furthermore, due to the relatively high ambient temperature in Libya compared with many European countries, overall fluid consumption by children is likely to be higher. As a result of nutrition transition by adopting a Westernised diet, the risk of non-communicable chronic diseases including oral diseases may be increased ${ }^{(1)}$.

There is an indication of an upward trend in dental caries prevalence in Libya as previous Libyan studies have shown that the mean number of decayed, filled and missing teeth for 12-year-old children increased from
$1 \cdot 17$ in $1996^{(2)}$ to 1.63 in $2000^{(3)}$, and to 1.68 in $2011^{(4)}$, possibly due to an increased availability of refined sugary products $^{(3)}$.

Only sparse data on the dietary intake of Libyan children, collected by questionnaire-based surveys, exist ${ }^{(5,6)}$ and there have been no prospective surveys of dietary intake in Libya. Furthermore, there are no data on the intake of dietary sugars or other dietary practices relevant to oral health.

Dietary free sugars intake is the most important aetiological factor in the development of dental caries. Free sugars include all added sugars plus those sugars naturally present in honey, syrups and fruit juices and concentrates ${ }^{(7)}$. There is strong consistent evidence of an association between the intake of free sugars and the development of dental caries ${ }^{(7,8-12)}$. Diet is arguably also the most important aetiological factor in the development of dental erosion. Dietary acids with a $\mathrm{pH}$ below 5.5 (the 'critical $\mathrm{pH}$ ') can cause demineralisation of the enamel and dissolution of the 
subsurface layers and subsequent loss of tooth structure ${ }^{(13)}$. Evidence from several epidemiological studies indicates an association between increased prevalence of dental erosion and the frequency of consumption of acidic soft drinks (i.e. carbonated beverages, fruit-based cordials, flavoured water and fruit juices) ${ }^{(14,15)}$. Dietary items such as fresh fruit, vinegar and salad dressings, pickled foods, fruit-flavoured confectionery and yoghurts also contain acids, although there is less epidemiological evidence to link consumption of these foods with dental erosion ${ }^{(11)}$. Many types of foods and soft drinks are acidic and also high in free sugars, so dental erosion and caries may be expected to occur together in a proportion of cases ${ }^{(16)}$. To prevent dental diseases in children the intakes of free sugars and of acidic drinks should be limited ${ }^{(7)}$.

In order to form a platform upon which oral health promotion can be based, and progress monitored, it is important to acquire information on current dietary intakes of sugars and acidic foods. Furthermore, information on the general properties of the diet with respect to the balance of macronutrients is important to ensure oral health programmes are compatible with general health needs.

The dearth of data on the intakes of free sugars and acidic foods and drinks by Libyan children means that currently no judgement on the potential risk to dental health can be made to inform the development of appropriate dietary programmes for oral disease prevention. In view of this and as part of a larger study investigating the oral health of children in Benghazi, a prospective dietary survey of 12-year-old children was conducted in 2008.

The aims of this dietary survey were to obtain dietary data (intakes of energy, macronutrients, sugars and acidic foods and drinks) for 12-year-old schoolchildren in Benghazi, Libya and to investigate any gender differences in these variables. The objectives were to: (i) randomly select a sample of schoolchildren to complete a $3 \mathrm{~d}$ estimated food diary; (ii) determine the mean daily intakes of protein, fat, carbohydrate and starch $(\mathrm{g} / \mathrm{d}$ and as a percentage contribution to daily energy intake); (iii) determine the mean daily intakes of total sugars, free sugars (non-milk extrinsic sugars) and intrinsic and milk sugars (IMS; i.e. those sugars that are naturally present in whole fruit, vegetables and grains and those naturally present in milk, yoghurt and cheese); (iv) estimate the mean daily contribution of free sugars consumed as meals and as snacks to total energy intake; and (v) estimate the average daily intakes of acidic drinks and foods.

\section{Materials and methods}

\section{The sample}

Benghazi is the second largest city in Libya after the capital, Tripoli. The city is divided into fifteen districts with rapidly progressing developments in all aspects of life. Benghazi is a very good example of a Libyan urban area comprising a population with different socio-economic, cultural and original backgrounds. Therefore, it was an appropriate site for the study and suitably representative of the Libyan urban population. At the time of the study, the total number of schoolchildren aged 12 years in Benghazi was approximately 7682 attending eighty-one public elementary schools ${ }^{(17)}$. Government-funded public schools comprised $90 \%$ of the total number of schools in Benghazi. There was no existing classification of social class in Benghazi which could be used to provide a sampling frame; therefore cluster sampling within schools was used. The numbers of schoolchildren and schools are not equal in each district in Benghazi, as they depend on the density of population in these districts. Therefore at least one school from each district and at least two schools from districts with six or more schools were randomly selected, producing a total of thirty-six schools representing the fifteen districts of Benghazi. Two people unrelated to the study from the researcher's institution helped to randomly select thirty-six schools by drawing out of a hat, one or two schools from each district. Then, a random selection of a sample of eleven girls and eleven boys from each school for whom parental consent had been obtained was made; these 792 children participated in the wider oral health survey. The sample size for the oral health study was calculated with a sample of 792 subjects; the $95 \%$ confidence interval was $\pm 4 \%$ able to detect a prevalence of erosion of $35 \pm 5 \%$ (standard error $2 \cdot 04 \%$ ). From the main sample a sub-sample of seven children was selected randomly from each of the thirty-six schools to participate in the dietary survey.

A target sample size for completion of the dietary survey was set to enable exploration between variables and detect moderately strong relationships. A sample of 175 provided $95 \%$ power to detect a correlation coefficient of 0.3 assuming a type I error rate of $5 \%$. To allow for attrition the target for recruitment was set at 252 .

\section{Etbical approval}

The study was conducted according to the guidelines laid down in the Declaration of Helsinki and all procedures involving human subjects were approved by the Health Ministry, Education Ministry and local authorities in Libya. Written informed consents were received from all participant children and parents.

\section{Collection of dietary data}

The participants were asked to complete a $3 \mathrm{~d}$ estimated food diary on three consecutive days, two weekdays (Thursday and Saturday) with one weekend day (Friday) between, and were interviewed on the fourth day (Sunday) to clarify the information in the diary and ascertain portion size eaten. The researcher met the participants in a group session in the classroom or in any available place in the 
school, explained to them how to complete the food diary and asked them to carry the food diary with them all the time during the three days. The researcher asked the participants to record everything they ate or drank, to write down the amount of food or drink consumed using household measures (i.e. plates, glasses, spoons), to record the time of consumption and to provide information about any medicines consumed. The importance of not changing their dietary pattern during the collection period was stressed. The interviews were undertaken on the first weekday following completion of the food diaries in order not to compromise the participants' ability to remember their dietary consumption. If the food diary was forgotten or the child was absent, the interview was carried out on the following day. Diaries were not included in the study if they were lost or returned incomplete.

The researcher used different sizes of domestic measures of quantities (cups, mugs, plates and spoons) to help the participants clarify the food portion size eaten. Typical food portion sizes for children aged 11-14 years in the $\mathrm{UK}^{(18)}$ and the food portion sizes guide book ${ }^{(19)}$ also facilitated portion size estimation where necessary. The weight of each child in light clothing without shoes was recorded using weighing scales (Seca, Hamburg, Germany).

There were no Libyan food tables available to use; therefore food diaries were coded according to McCance and Widdowson's The Composition of Foods ${ }^{(20)}$. For Libyan foods for which a directly matched code did not exist, the composition of foods and supplements was determined using 'best matches'. For this process, Libyan recipes were consulted in order to estimate the proportion of each ingredient present. For instance, using a Libyan recipe for a traditional meal made with vine leaves stuffed with rice and meat, the proportion of meat, rice and other components was determined. The vine leaves and rice component ( $80 \%$ of the recipe) was coded as 'vine leaves stuffed with rice' which exists as a code in the UK food tables. The meat component (20\% of the recipe) was coded as 'cooked minced beef'. The same method was used for a Libyan dish comprising aubergine and peppers stuffed with rice and meat.

The coded data were entered into a pre-existing Microsoft ${ }^{\circledR}$ Access database into which the food composition tables were integrated, and intakes of nutrients, acidic foods and drinks were derived using purpose-written programs. All foods consumed by the participants were considered as consumed as meals or snacks. A meal was defined as any intake including at least three of these criteria: (i) a number of items eaten together and consisting of at least three items; (ii) making a major contribution to the energy intake for that day; (iii) eaten at recognised mealtimes; (iv) eaten with a knife, fork or spoon; and (v) usually consumed over a period of more than $15 \mathrm{~min}$. A snack was defined as any intake not meeting the aforementioned criteria for a meal ${ }^{(21,22)}$.

\section{Data analysis}

Dietary data were transferred for analysis into the statistical software package SPSS $15 \cdot 0$ for Windows. The normality of distribution of the data was assessed using the one-sample Kolmogorov-Smirnov $Z$ test. For continuous variables that were normally distributed, data were presented as mean with standard deviation and 95\% confidence interval. For continuous variables that had a skewed distribution, data were presented as the median with the interquartile range (IQR). Comparison between genders was carried out using an unpaired $t$ test for normally distributed data and the Mann-Whitney test for skewed data.

\section{Validation of reported energy intake}

The physical activity level (PAL) was calculated for each participant by dividing the reported energy intake by BMR (which was derived from body weight data using the Schofield equations) $)^{(23)}$. PAL was used to identify the proportion of participants who may have under- or over-reported dietary intake. The following cut-off points proposed for children aged 6-18 years were used to identify 'under-reporters' and 'over-reporters' for dietary intake among the children ${ }^{(24)}$. For boys: under-reporters, $\mathrm{PAL}<1 \cdot 39$; over-reporters, $\mathrm{PAL}>2 \cdot 24$. For girls: underreporters, $\mathrm{PAL}<1 \cdot 30$; over-reporters, $\mathrm{PAL}>2 \cdot 10$.

\section{Results}

Of the 252 food diaries distributed, forty-nine food diaries were returned incomplete, sixteen children forget or lost the food dairies and seven children were absent on several occasions when the diaries were being collected. Therefore, complete food diaries were obtained from a total of 180 participants ( $71 \%$ of the sample) of whom ninety-two (51\%) were boys and eighty-eight (49\%) were girls. The mean age of the 180 children was $12 \cdot 3$ (sD $0 \cdot 29$ ) years. The mean age was 11.7 (SD 0.31 ) years for boys and $11.9(\mathrm{sD} 0.29)$ years for girls. The mean weight was $42 \cdot 7$ (sD $4 \cdot 06$ ) $\mathrm{kg}$ for boys and $42 \cdot 9$ (sD 5.02) $\mathrm{kg}$ for girls.

\section{Validation of the dietary data}

The mean PAL was $1 \cdot 30$ (SD 0.32), 1.20 (SD 0.32) for boys and 1.30 (SD 0.29) for girls. Fifty-one boys (55\%) had PAL $<1.30$ and thirty-two girls (36\%) had PAL $<1 \cdot 39$.

\section{Intakes of energy and macronutrients}

A one-sample Kolmogorov-Smirnov $Z$ test showed that data for intakes of protein, fat, carbohydrate and starch were normally distributed. Data for these are presented in Table 1 . The mean daily energy intake was $7 \cdot 01$ (SD 1.54$)$ $\mathrm{MJ} / \mathrm{d} ; 7 \cdot 05$ (sD 1.64) MJ/d for boys and $6.96(\mathrm{sD} 1.44) \mathrm{MJ} / \mathrm{d}$ for girls (1675 (SD 368) kcal/d; 1686 (SD 393) kcal/d for boys and 1663 (SD 343) kcal/d for girls). This difference between boys and girls was not statistically significant $(P=0 \cdot 465$; Table 2$)$. 
Table 1 Mean, standard deviation, median, minimum, maximum and $95 \%$ confidence interval for daily energy intake, daily intakes and percentage contributions of fat, carbohydrate, protein and NSP (dietary fibre) of the participants: 180 schoolchildren aged 12 years, Benghazi, Libya, 2008

\begin{tabular}{lcccccc}
\hline & Mean & SD & Median & Minimum & Maximum & $95 \% \mathrm{Cl}$ \\
\hline Energy intake (kJ/d) & 7008 & 1540 & 6778 & 4075 & 11661 & 6778,7234 \\
Energy intake (kcal/d) & 1675 & 368 & 1620 & 974 & 2787 & 1620,1729 \\
Carbohydrate (g/d) & $237 \cdot 2$ & $51 \cdot 0$ & $230 \cdot 4$ & $145 \cdot 7$ & $402 \cdot 5$ & $229 \cdot 7,244 \cdot 7$ \\
$\%$ energy from carbohydrate & $54 \cdot 0$ & $4 \cdot 7$ & $54 \cdot 5$ & $41 \cdot 4$ & $64 \cdot 3$ & $53 \cdot 3,54 \cdot 7$ \\
Protein (g/d) & $64 \cdot 8$ & $15 \cdot 8$ & $63 \cdot 2$ & $36 \cdot 7$ & $130 \cdot 9$ & $62 \cdot 8,67 \cdot 8$ \\
\% energy from protein & $15 \cdot 7$ & $2 \cdot 2$ & $15 \cdot 8$ & $10 \cdot 9$ & $21 \cdot 0$ & $15 \cdot 4,16 \cdot 1$ \\
Fat (g/d) & $58 \cdot 2$ & $17 \cdot 3$ & $56 \cdot 3$ & $27 \cdot 1$ & $129 \cdot 9$ & $55 \cdot 6,60 \cdot 7$ \\
$\%$ energy from fat & $30 \cdot 2$ & $4 \cdot 6$ & $29 \cdot 7$ & $20 \cdot 9$ & $44 \cdot 2$ & $29 \cdot 6,30 \cdot 9$ \\
NSP (dietary fibre) (g/d) & $9 \cdot 0$ & $2 \cdot 5$ & $8 \cdot 1$ & $4 \cdot 0$ & $17 \cdot 0$ & $8 \cdot 2,8 \cdot 9$ \\
\hline
\end{tabular}

Table 2 Mean, standard deviation, 95\% confidence interval and significance of the difference $(P)$ for daily intakes of energy and macronutrients by gender: 180 schoolchildren aged 12 years, Benghazi, Libya, 2007

\begin{tabular}{|c|c|c|c|c|c|c|c|c|c|}
\hline & \multicolumn{4}{|c|}{ Boys ( $n$ 92) } & \multicolumn{4}{|c|}{ Girls ( $n$ 88) } & \multirow[b]{2}{*}{$P$} \\
\hline & Mean & SD & Median & $95 \% \mathrm{Cl}$ & Mean & SD & Median & $95 \% \mathrm{Cl}$ & \\
\hline Energy intake $(\mathrm{kJ} / \mathrm{d})$ & 7054 & 1644 & 6866 & 6715,7393 & 6958 & 1435 & 6757 & 6653,7259 & 0.466 \\
\hline Energy intake $(\mathrm{kcal} / \mathrm{d})$ & 1686 & 393 & 1641 & 1605,1767 & 1663 & 343 & 1615 & 1590,1735 & 0.465 \\
\hline Protein $(\mathrm{g} / \mathrm{d})$ & $65 \cdot 8$ & $17 \cdot 7$ & $63 \cdot 3$ & $62 \cdot 0,69 \cdot 4$ & $64 \cdot 9$ & $16 \cdot 2$ & $63 \cdot 1$ & $61 \cdot 4,68 \cdot 3$ & 0.789 \\
\hline Fat $(g / d)$ & $59 \cdot 1$ & $19 \cdot 1$ & $56 \cdot 2$ & $55 \cdot 1,63 \cdot 0$ & $57 \cdot 3$ & $15 \cdot 4$ & $56 \cdot 3$ & $54 \cdot 0,60 \cdot 5$ & 0.877 \\
\hline Carbohydrate (g/d) & $237 \cdot 7$ & $51 \cdot 5$ & $231 \cdot 0$ & $227 \cdot 0,248 \cdot 3$ & $236 \cdot 7$ & $50 \cdot 7$ & $227 \cdot 0$ & $225 \cdot 9,247 \cdot 0$ & 0.899 \\
\hline Total sugars $(g / d)$ & $89 \cdot 7$ & $30 \cdot 5$ & $87 \cdot 8$ & $83 \cdot 3,95 \cdot 9$ & $90 \cdot 7$ & $33 \cdot 4$ & $87 \cdot 5$ & $83 \cdot 6,97 \cdot 7$ & 0.824 \\
\hline Free sugars $(\mathrm{g} / \mathrm{d})$ & $54 \cdot 3$ & $24 \cdot 3$ & $49 \cdot 5$ & $45 \cdot 3,59 \cdot 3$ & $57 \cdot 5$ & $26 \cdot 9$ & $52 \cdot 5$ & $51 \cdot 7,63 \cdot 1$ & 0.465 \\
\hline IMS $(g / d)$ & $35 \cdot 3$ & $19 \cdot 3$ & $30 \cdot 5$ & $31 \cdot 3,29 \cdot 7$ & $33 \cdot 3$ & $16 \cdot 7$ & $31 \cdot 5$ & $29 \cdot 7,36 \cdot 7$ & 0.468 \\
\hline Total intake of acidic items $(\mathrm{g} / \mathrm{d})$ & $244 \cdot 0$ & $197 \cdot 8$ & $203 \cdot 7$ & $203 \cdot 0,285 \cdot 0$ & $249 \cdot 0$ & $177 \cdot 9$ & $202 \cdot 0$ & $211 \cdot 0,286 \cdot 0$ & 0.015 \\
\hline Acidic drinks (g/d) & $188 \cdot 6$ & $175 \cdot 0$ & $133 \cdot 3$ & $152 \cdot 0,224 \cdot 0$ & $187 \cdot 0$ & $153 \cdot 7$ & $176 \cdot 7$ & $154 \cdot 0,219 \cdot 0$ & 0.456 \\
\hline All confectionery $(\mathrm{g} / \mathrm{d})$ & $13 \cdot 2$ & $10 \cdot 2$ & $8 \cdot 1$ & $7 \cdot 6,17 \cdot 7$ & $17 \cdot 5$ & $10 \cdot 0$ & $17 \cdot 1$ & $12 \cdot 2,22 \cdot 6$ & 0.389 \\
\hline Total intake of acidic items with meals $(\mathrm{g} / \mathrm{d})$ & $119 \cdot 3$ & $118 \cdot 0$ & $77 \cdot 8$ & $94 \cdot 9,143 \cdot 8$ & $122 \cdot 3$ & $107 \cdot 0$ & $110 \cdot 0$ & $99 \cdot 6,145 \cdot 0$ & 0.288 \\
\hline Total intake of acidic items as snacks $(\mathrm{g} / \mathrm{d})$ & $125 \cdot 1$ & $134 \cdot 0$ & $78 \cdot 2$ & $97 \cdot 3,152 \cdot 9$ & $126 \cdot 5$ & $129 \cdot 0$ & $84 \cdot 7$ & $99 \cdot 0,153 \cdot 9$ & 0.300 \\
\hline
\end{tabular}

IMS, intrinsic and milk sugars.

Table 3 Mean, standard deviation and $95 \%$ confidence interval for daily intakes of total sugars, IMS and free sugars, percentage contributions of total sugars, IMS and free sugars to daily energy intake, and percentage contributions of free sugars from snacks and meals to daily energy intake: 180 schoolchildren aged 12 years, Benghazi, Libya, 2008

\begin{tabular}{lccc}
\hline & Mean & SD & $95 \% \mathrm{Cl}$ \\
\hline Total sugars $(\mathrm{g} / \mathrm{d})$ & $90 \cdot 3$ & $31 \cdot 9$ & $85 \cdot 4,94 \cdot 8$ \\
IMS $(\mathrm{g} / \mathrm{d})$ & $34 \cdot 3$ & $18 \cdot 0$ & $31 \cdot 6,36 \cdot 9$ \\
Free sugars $(\mathrm{g} / \mathrm{d})$ & $56 \cdot 0$ & $25 \cdot 6$ & $52 \cdot 1,59 \cdot 6$ \\
\% contribution to total energy from & & $5 \cdot 5$ & $19 \cdot 5,21 \cdot 2$ \\
$\quad$ Total sugars & $20 \cdot 4$ & $3 \cdot 8$ & $7 \cdot 2,8 \cdot 4$ \\
IMS & $7 \cdot 8$ & $4 \cdot 7$ & $11 \cdot 8,13 \cdot 2$ \\
Free sugars & $12 \cdot 6$ & $9 \cdot 9$ & $28 \cdot 6,24 \cdot 1$ \\
\% contribution to total energy of free sugars from & $22 \cdot 7$ & $6 \cdot 8,8 \cdot 0$ \\
Snacks & $7 \cdot 5$ & $4 \cdot 2$ & \\
Meals & & & 2 \\
\hline
\end{tabular}

IMS, intrinsic and milk sugars.

The mean daily intakes of carbohydrate, fat and protein were 237 (SD 51) g/d, 58 (sD 17) g/d and 65 (sD 16) g/d, respectively. Carbohydrate made the largest contribution to daily food intake $(54 \cdot 0 \%)$, followed by fat $(30 \cdot 2 \%)$ and protein $(15 \cdot 7 \%)$. Starch comprised most of the carbohydrate intake, contributing $32 \cdot 8 \%$ to energy intake. The mean daily intake of dietary fibre, NSP, was $9 \cdot 0$ (SD $2 \cdot 5$ ) g/d. The mean daily intakes of protein, fat, carbohydrate were higher in boys than girls although there were no statistically significant differences between genders (Table 2).

\section{Sugars intake}

Data for intake of total sugars, free sugars and IMS were normally distributed (Table 3 ). Total sugars provided $20 \cdot 4 \%$ of the daily energy intake, free sugars $12 \cdot 6 \%$ and IMS $7 \cdot 8 \%$.

The mean daily intake of total sugars was 90 (sD 32) g/d, mainly in the form of free sugars $(56$ (SD 26) g/d) with $34(\mathrm{SD} 18) \mathrm{g} / \mathrm{d}$ in the form of IMS. Free sugars in snacks contributed $22.7 \%$ of the daily energy intake, while free sugars in meals contributed $7 \cdot 5 \%$ of the daily energy 
Table 4 Mean, standard deviation, median, minimum, maximum and IQR for daily intakes of acidic drinks, fruits, confectionery, total acidic items and total acidic foods with meals and as snacks: 180 schoolchildren aged 12 years, Benghazi, Libya, 2008

\begin{tabular}{|c|c|c|c|c|c|c|}
\hline & Mean & SD & Median & Minimum & Maximum & IQR \\
\hline Acidic drinks (g/d) & $188 \cdot 0$ & $164 \cdot 5$ & $145 \cdot 5$ & $0 \cdot 0$ & $793 \cdot 3$ & $67 \cdot 0-267 \cdot 0$ \\
\hline Energy $(\mathrm{kJ} / \mathrm{d})$ from acidic drinks & $248 \cdot 6$ & $150 \cdot 7$ & $252 \cdot 8$ & $3 \cdot 9$ & $574 \cdot 2$ & $160 \cdot 0-330 \cdot 0$ \\
\hline Fruits $(\mathrm{g} / \mathrm{d})$ & $12 \cdot 0$ & $8 \cdot 6$ & $10 \cdot 2$ & $2 \cdot 2$ & $50 \cdot 5$ & $4 \cdot 5-15 \cdot 0$ \\
\hline Confectionery $(\mathrm{g} / \mathrm{d})$ & $13 \cdot 6$ & $10 \cdot 0$ & $11 \cdot 4$ & $0 \cdot 4$ & $51 \cdot 5$ & $6 \cdot 1-18 \cdot 9$ \\
\hline Energy $(\mathrm{kJ} / \mathrm{d})$ from acidic food & $220 \cdot 9$ & $62 \cdot 7$ & $210 \cdot 9$ & $27 \cdot 1$ & $568 \cdot 8$ & $190 \cdot 0-252 \cdot 0$ \\
\hline Total intake of acidic items $(\mathrm{g} / \mathrm{d})$ & $246 \cdot 5$ & $187 \cdot 8$ & $203 \cdot 3$ & $0 \cdot 0$ & $966 \cdot 7$ & $115 \cdot 0-355 \cdot 0$ \\
\hline Energy $(\mathrm{kJ} / \mathrm{d})$ from total acidic foods & $421 \cdot 8$ & $355 \cdot 8$ & $330 \cdot 0$ & $3 \cdot 9$ & $2194 \cdot 5$ & $190 \cdot 0-565 \cdot 0$ \\
\hline Total intake of acidic items with meals $(\mathrm{g} / \mathrm{d})$ & $120 \cdot 8$ & $112 \cdot 6$ & $104 \cdot 3$ & $0 \cdot 0$ & $560 \cdot 0$ & $34 \cdot 0-177 \cdot 0$ \\
\hline$\%$ of energy intake from total acidic foods consumed with meals & $3 \cdot 6$ & $2 \cdot 5$ & $3 \cdot 3$ & $0 \cdot 1$ & $14 \cdot 9$ & $1 \cdot 6-4 \cdot 7$ \\
\hline Total intake of acidic items as snacks ( $\mathrm{g} / \mathrm{d}$ ) & $125 \cdot 8$ & $131 \cdot 5$ & $83 \cdot 3$ & $0 \cdot 0$ & $674 \cdot 0$ & $3 \cdot 0-200 \cdot 0$ \\
\hline$\%$ of energy intake from total acidic foods consumed as snacks & $3 \cdot 6$ & $2 \cdot 8$ & $2 \cdot 8$ & $0 \cdot 1$ & $16 \cdot 2$ & $1 \cdot 6-5 \cdot 0$ \\
\hline
\end{tabular}

IQR, interquartile range.

intake (Table 3). The mean free sugars intake corresponded to $20 \cdot 4 \mathrm{~kg} /$ year per person and it was the major contributor to the total sugars consumption among Libyan children (12.6\%). The data showed no statistically significant differences between boys and girls for intake of sugars (Table 2).

\section{Consumption of acidic foods and drinks}

A one-sample Kolmogorov-Smirnov $Z$ test showed that data relating to the consumption of acidic foods and drinks were not normally distributed. Table 4 shows that the median daily intake of total acidic food and drink was $203 \cdot 3$ (IQR 115-355) g/d. Acidic drinks were the main source of dietary acids, with a median daily intake of 146 (IQR 67-267) g/d. The intake of acidic food was $58 \mathrm{~g} / \mathrm{d}$, with a median daily consumption of fresh fruits (excluding fruit juices) of $10 \cdot 2$ (IQR 4.5-15·0) g/d. The median daily intake of acidic confectionery was $11 \cdot 4$ (IQR 6·1-18.9) g/d (Table 4).

\section{Discussion}

The present study is the first to report both macronutrient intakes and dietary intakes of relevance to dental health in children from Libya.

Three-day food diaries are a validated prospective method for collecting dietary data and are justified for use in children ${ }^{(21,22,25,26)}$. The food diary method is not only suited to providing a good estimate of the mean intake of a group, but it also provides more accurate and detailed information about the quantity, time and pattern of consumption of foods and drinks which is important when investigating dietary patterns of relevance to dental health. The average PAL for all the participants and for girls was $1 \cdot 30$, which is not indicative of misreporting. However, the mean PAL for boys was $1 \cdot 20$, suggesting that there was under-reporting ${ }^{(24)}$. In a UK survey in 2000 , the PAL for girls and boys was reported as 1.38 which is higher than the present figure ${ }^{(22)}$.

The mean daily intake of total acidic foods was significantly lower in under-reporters than in normal reporters which, together with the potential under-reporting of sugars intake, might suggest misreporting of sugared acidic drinks. A dietary survey of 11-12-year-old children in northeast England in 2000 found that 23\% of boys and 18\% of girls had PAL values of $<1^{(22)}$. There are many reasons which may account for the under-reporting and a common explanation is that some participants changed their diet diary intake during the period of recording ${ }^{(27)}$, or that children may have forgotten to report between-meal sugary snacks and drinks. However, selective under-reporting of 'unhealthy items' cannot be ruled out in this instance.

The categorisation of meals and snacks adopted in the present study was similar to that previously defined by Fletcher $^{(28)}$, which stated that a meal must meet at least three of the following criteria: a number of items eaten together and consisting of at least three items, making a major contribution to the energy intake for that day, eaten at recognised mealtimes and usually be consumed over a period of more than $15 \mathrm{~min}$. However, the present study also considered the general lifestyle of Libyan children in Benghazi when defining meals and snacks. For example, schoolchildren attend school from 08.00 hours in the morning, and therefore usually have a light breakfast at home and take a packed meal with them to school or buy a meal from the school canteen at the 10.30 hours break. Therefore for the present analysis, the light 'breakfast' consumed at home was considered a snack and the food consumed in school at the 10.30 hours break time was considered the first meal. Children return home from school between 13.00 and 15.00 hours when they usually consume the main meal of the day and have a second meal between 18.00 and 21.00 hours.

In the present study, the daily energy intake was $7 \cdot 01 \mathrm{MJ} / \mathrm{d} ; 7 \cdot 05 \mathrm{MJ} / \mathrm{d}$ for boys and $6.96 \mathrm{MJ} / \mathrm{d}$ for girls $(1675 \mathrm{kcal} / \mathrm{d} ; 1686 \mathrm{kcal} / \mathrm{d}$ for boys and $1663 \mathrm{kcal} / \mathrm{d}$ for girls). There are no Libyan dietary guidelines to enable comparison with these values, but the values are lower than the UK Estimated Average Requirement for 11-14-year-olds of $9 \cdot 26 \mathrm{MJ} / \mathrm{d}(2214 \mathrm{kcal} / \mathrm{d})$ for boys and $7.92 \mathrm{MJ} / \mathrm{d}(1892 \mathrm{kcal} / \mathrm{d})$ for girls ${ }^{(29)}$. The values for energy intake in the present study were lower than 
those previously reported for children of similar age from different countries. In a study carried out to assess the dietary intake for 11-16-year-old children in Switzerland through a $3 \mathrm{~d}$ food diary, the mean daily energy intake was $8025 \mathrm{~kJ} / \mathrm{d}$ for girls and $9350 \mathrm{~kJ} / \mathrm{d}$ for boys ${ }^{(30)}$. The mean energy intakes of the Libyan children were slightly lower those reported from a study of 424 children aged 11-12 years in north-east England that also assessed diet using estimated food diaries, in which mean energy intake for boys was $8 \cdot 45 \mathrm{MJ} / \mathrm{d}$ and for girls was $7 \cdot 60 \mathrm{MJ} / \mathrm{d}^{(31)}$. The lower values in the present study are likely to be due to the aforementioned 'under-reporting'.

Carbohydrates made the largest contribution to energy intake $(54.0 \%)$ in the diets of the Libyan children, followed by fat $(30 \cdot 2 \%)$ and protein $(15 \cdot 7 \%)$. These contributions were in line with general nutritional guidelines ${ }^{(7)}$. In the present study, the daily intakes of carbohydrate, fat and protein were 238, 59 and $66 \mathrm{~g} / \mathrm{d}$, respectively, for boys and 237, 57 and $65 \mathrm{~g} / \mathrm{d}$, respectively, for girls. When these results are compared with the aforementioned Swiss study $^{(32)}$, it was found that intakes of carbohydrate and fat were lower but intake of protein was higher than for Swiss children.

The mean daily intake of total sugars in the present study was $90 \mathrm{~g} / \mathrm{d}$. Total sugars contributed $20 \%$ to daily energy intake, which was slightly lower than the $22 \%$ found in a study in the $\mathrm{UK}^{(33)}$.

The present study showed the mean daily intake of free sugars for all participants to be $56 \mathrm{~g} / \mathrm{d}$ (extrapolation of this figure produces an estimate of mean free sugars intake of $20.4 \mathrm{~kg}$ /year per person), which is lower than figure of $82 \mathrm{~g} / \mathrm{d}$ reported in a dietary survey of 12-year-old children in the $\mathrm{UK}^{(33)}$ and half the intake reported in 14-year-old Brazilian schoolchildren $(111 \mathrm{~g} / \mathrm{d})^{(26)}$. On the other hand, the daily intake of free sugars was higher than the WHO recommended population average of no more than $15-20 \mathrm{~kg} /$ year per person ${ }^{(7)}$. The free sugars intake in the present study was the major contributor to the total sugars consumption among Libyan children (12.6\%), which was lower than the $17 \cdot 7 \%$ found in the Brazilian study $^{(26)}$ and lower than the figure of $16 \%$ in the UK survey ${ }^{(33)}$, but higher than the Dietary Reference Value for daily energy intake from free sugars $(10 \%)^{(29)}$.

The mean daily intakes of free sugars and IMS in the present study were respectively 54 and $35 \mathrm{~g} / \mathrm{d}$ for the ninety-two boys, while for the eighty-eight girls the intakes were 58 and $33 \mathrm{~g} / \mathrm{d}$. These intakes were lower than those found in the UK National Diet and Nutrition Survey of young people aged 11-14 years, in which free sugars intake was $90 \mathrm{~g} / \mathrm{d}$ in boys and $73 \mathrm{~g} / \mathrm{d}$ in girls and the mean contribution to daily energy intake was $16 \cdot 9 \%{ }^{(34)}$.

Of concern is the finding that the free sugars in snacks made a higher contribution to daily energy intake (23\%) than free sugars consumed at mealtimes (8\%), which suggests that most free sugars were consumed in between meals.
The median daily total intake of acidic foods and drinks among Libyan children was $203 \mathrm{~g} / \mathrm{d}$; half that reported for 14-year-old Brazilian children $(400 \mathrm{~g} / \mathrm{d})$, despite similar methodologies being used to collect dietary information in the two studies ${ }^{(26)}$.

Acidic drinks were the main source of total dietary acids, with a median daily intake of $146 \mathrm{~g} / \mathrm{d}$ in the present study. This figure was lower than the one observed in the Brazilian children $(340 \mathrm{~g} / \mathrm{d})^{(26)}$. Moreover, this intake was much lower than that among 11-14-year-olds in the UK National Diet and Nutrition Survey ${ }^{(27)}$, which found that the mean daily intakes of carbonated drinks, concentrated and ready-to-drink soft drinks, and fruit juices were 240 , 352 and $54 \mathrm{~g} / \mathrm{d}$, respectively.

In the present study, the median daily consumption of fresh fruits was only $10 \mathrm{~g} / \mathrm{d}$ which suggests an intake well below the current recommendation for intake of fruits and vegetables of $>400 \mathrm{~g} / \mathrm{d}^{(7)}$. However, the possibility that the children ate lots of vegetables cannot be ruled out. The low intake of fruit appears to be consistent with dietary patterns observed for children in other studies. Approximately $14 \%$ of 418 children aged 14 years in Birmingham, UK never consumed fruit ${ }^{(35)}$. The median daily intake of fruits in the present study was much lower than the daily fruit intake observed in another study for 11-14 year-olds in the UK, which was $36 \mathrm{~g} / \mathrm{d}^{(27)}$. It is difficult to make between study comparisons due to the use of different methodologies and age groups studied.

The present study has focused on the dietary intakes of children residing in urban areas and further research is needed to investigate the dietary habits of children in rural areas of Libya.

\section{Conclusions}

The contributions to energy intake from macronutrients (carbohydrate, fat and protein) observed in this sample of Libyan children were in line with general nutritional guidelines $^{(7)}$. However, daily consumption of fresh fruits was very low and an effective means for increasing consumption should be found.

Overall the intake of acidic foods and drinks was lower than previously reported; but in order to prevent tooth erosion, these levels of intake should not be increased further.

The mean daily intake of free sugars corresponds to $20 \cdot 4 \mathrm{~kg} /$ year per person ( $12 \cdot 6 \%$ of energy intake), which is above the WHO recommended threshold for free sugars intake of no more than $15-20 \mathrm{~kg} /$ year per person or $10 \%$ of total dietary energy ${ }^{(7)}$. Although these levels of consumption were not as high as those in some industrialised countries, efforts to reduce levels of and prevent further increases in intake of free sugars are warranted to protect the dental health of children. National, community and school-based strategies to limit the intake of acidic drinks and reduce the intake of free sugars by children are needed. 


\section{Acknowledgements}

Sources of funding: The authors acknowledge the Ministry of Higher Education, Libya for financially sponsoring the study. Ethics: Ethical clearance and permissions were obtained from the Libyan Health Ministry and Education Ministry. Conflicts of interest: There are no conflicts of interest to declare. Author' contributions: A.M., P.W. and P.M. conceptualised the study and supervised the researcher, R.H., who collected and analysed the data as part of her PhD. R.H. and P.M. co-wrote the manuscript with substantial contributions from A.M. and P.W. Acknowledgements: The authors thank all the schoolchildren, parents, school staff and local authorities in Benghazi for their cooperation with the study. Thanks are also extended to Dr Simon Kometa for his advice with the statistical analysis.

\section{References}

1. Elmehdawi R \& Albarsha A (2012) Obesity in Libya: a review. Libyan J Med 7, 19086.

2. Hawew RM, Ellwood RP, Hawley GM et al. (1996) Dental caries in children from two Libyan cities with different levels of fluoride in their drinking water. Community Dent Health 13, 175-177.

3. Sharbati M, Meidan T \& Sudani O (2000) Oral health practices and dental caries among Libyan pupils, Benghazi (1993-94). East Mediterr Health J 6, 997-1004.

4. Huew R, Waterhouse PJ, Moynihan PJ et al. (2011) Prevalence and severity of dental caries in Libyan schoolchildren. Int Dent J 61, 217-223.

5. Omar S \& Pitts N (1991) Oral hygiene, gingivitis and periodontal status of Libyan school children. Community Dent Health 8, 329-333.

6. Hawew R (1995) An assessment of the dental health of six and twelve year old children in Benghazi and Jardinah, Libya. MSc Thesis, University of Manchester.

7. World Health Organization (2003) Diet, Nutrition and the Prevention of Chronic Diseases. Joint WHO/FAO Expert Consultation. WHO Technical Report Series no. 916. Geneva: WHO.

8. Rugg-Gunn AJ \& Hackett AF (1993) Nutrition and Dental Health. Oxford: Oxford University Press.

9. Sheiham A (2001) Dietary effects on dental dieases. Public Health Nutr 4, 569-591.

10. Moynihan PJ (2002) Dietary advice in dental practice. $\mathrm{Br}$ Dent J 193, 563-568.

11. Moynihan PJ \& Petersen P (2004) Diet, nutrition and the prevention of dental diseases. Public Health Nutr 7, 201-226.

12. Yabao RN, Duante CA, Velandria FV et al. (2005) Prevalence of dental caries and sugar consumption among 6-12-y-old schoolchildren in La Trinidad, Benguet, Philippines. Eur J Clin Nutr 59, 1429-1438.

13. Barron RP, Carmichael RP, Marcon MA et al. (2003) Dental erosion in gastroesophageal reflux disease. J Can Dent Assoc 69, 84-89.

14. O'Sullivan E \& Curzon M (2000) A comparison of acidic dietary factors in children with and without dental erosion. ASDC J Dent Child 67, 186-192.
15. Al-Dlaigan YH, Shaw L, Smith AJ et al. (2001) Vegetarian children and dental erosion. Int J Paediatr Dent 11, 184-192.

16. Al-Malik MI, Holt RD \& Bedi R (2002) Erosion, caries and rampant caries in preschool children in Jeddah, Saudi Arabia. Commun Dent Oral Epidemiol 30, 16-23.

17. Great Socialist People's Libyan Arab Jamhoriya, General Authority of Information (2007) Preliminary Results of General Population Census 2006. Benghazi: GAI.

18. Wrieden W, Longbottom, Adamson AJ et al. (2008) Estimation of typical food portion sizes for children of different ages in Great Britain. Br J Nutr 99, 1344-1353.

19. Crawley H, Mills A, Patel S et al. (1993) Food Portion Sizes. London: HMSO.

20. Food Standards Agency (2002) McCance and Widdowson's The Composition of Foods, 6th ed. Cambridge: Royal Society of Chemistry.

21. Hackett AF, Rugg-Gunn AJ, Appleton DR et al. (1984) Sugars-eating habits of 405 11-14 year-old English children. Br J Nutr 51, 347-356.

22. Fletcher ES, Rugg-Gunn AJ, Matthews JN et al. (2004) Changes over 20 years in macronutrient intake and body mass index in 11- to 12-year-old adolescents living in Northumberland. Br J Nutr 92, 321-333.

23. Garrow JS, James WP \& Ralph A (editors) (2000) Human Nutrition and Dietetics, 10th ed. Edinburgh: Churchill Livingstone.

24. Torun B, Davies P, Livingstone MB et al. (1996) Energy requirements and dietary energy recommendations for children and adolescents 1 to 18 years old. Eur J Clin Nutr 50, 37-81.

25. Adamson A, Rugg-Gunn AJ, Butler $\mathrm{T}$ et al. (1992) Nutritional intake, height and weight of 11-12 year-old Northumbrian children in 1990 compared with information obtained in 1980. Br J Nutr 68, 543-563.

26. Auad S (2006) Dental erosion in Brazilian schoolchildren and its association with dental caries and potential risk factors. PhD Thesis, Newcastle University.

27. Walker A, Gregory J, Bates CJ et al. (2000) National Diet and Nutrition Survey: Young People Aged 4-18 years. vol. 2: Report of the Oral Health Survey, p. 292. London: The Stationery Office.

28. Fletcher ES (2003) Changes in the Diets of Adolescents. Newcastle upon Tyne: University of Newcastle upon Tyne, School of Clinical Medical Sciences.

29. Department of Health (1991) Dietary Reference Values for Food Energy and Nutrients for the United Kingdom. Report on Health and Social Subjects no. 41. London: HSMO.

30. Decarli B, Cavadini C, Grin J et al. (2000) Food and nutrient intakes in a group of 11 to 16 year old Swiss teenagers. Int J Vitam Nutr Res 70, 139-147.

31. Zohouri FV, Rugg-Gunn AJ, Fletcher ES et al. (2004) Changes in water intake of Northumbrian adolescents 1980 to 2000. Br Dent J 196, 547-552.

32. Aeberli I, Kaspar M \& Zimmermann MB (2007) Dietary intake and physical activity of normal weight and overweight 6-to 14-year-old Swiss children. Swiss Med Wkly 137, 424.

33. Rugg-Gunn AJ, Fletcher ES, Matthews JN et al. (2007) Changes in consumption of sugars by English adolescents over 20 years. Public Health Nutr 10, 354-363.

34. Gregory J, Lowe S, Bates CJ et al. (2000) National Diet and Nutrition Survey: Young People Aged 4 to 18 Years. vol. 1: Report of the Diet and Nutrition Survey. London: The Stationery Office.

35. Al-Dlaigan YH, Shaw L \& Smith A (2001) Dental erosion in a group of British 14 year-old school children. Part II: influence of dietary intake. Br Dent J 190, 258-261. 